\title{
IN VITRO BOND STRENGTH OF DENTAL RESIN-COMPOSITES: A REVIEW OF AFFECTING VARIABLES
}

\author{
Samy M. El-Safty*
}

\begin{abstract}
The objective of this article was to in-depth review the literature regarding the different parameters that critically influence the "in vitro" bond strength between the tooth structure and restorative resin-composites. The need to do such a review was due to inconsistencies between the bond strength results obtained from studies for the same products. One can justify such a difference between results on the basis that authors do not standardize all variables that may have a direct effect on the results. Some of these variables include resin-composite material used, adhesive system applied, type of bond strength test (macro or micro, shear or tensile), bonding area, storage time and conditions, load application method, mode of failure, and other testing parameters. Understanding of such issues will enable researchers to properly select and conduct the bond strength test and correctly interpret the resulting data.
\end{abstract}

KEYWORDS: Bond strength, Resin-composite, Adhesive system, Bonding area, Type of test, Smear layer, Storage Conditions.

\section{INTRODUCTION}

The establishment of a strong and durable bond between the tooth structure and the restorative material has been a long-term goal of modern dentistry ${ }^{[1]}$. The extensive use of resin-composite materials in tooth restoration is primarily due to their popularity for both clinicians and patients. Some of the most prominent characteristics of these restorative materials include their color which is similar to that of a natural tooth, their good physical properties and capability of being used in conservative cavity preparation. A strong and durable bond between the resin-composite and dentin determine, to a great extent, the success of its restoration ${ }^{[2]}$.

Over the years, laboratory investigations have been used extensively by dental clinicians to choose the best approaches and products that can achieve most desirable results in their daily practice. However, there has been a poor correlation between bond strength tests and the clinical performance of dental adhesive systems used and clinical procedures applied ${ }^{[3,4]}$.

* Lecturer at Biomaterials department, School of dentistry, Tanta University, Tanta, Egypt. 
Investigating tooth/restoration bond strength has been traditionally conducted by preparing one test specimen per tooth which is then loaded up to failure using either tensile or shear type of loading. Recently, there is a more common approach which enables researchers to load multiple test specimens from a single tooth in either a micro-tensile ( $\mu \mathrm{TBS}$ ) or a micro-shear $(\mu \mathrm{SBS})$ manner ${ }^{[5]}$.

However, there are multiple variables that must be taken into consideration while testing the tooth/ restoration bond. This is because if an adhesion research conducted in a non-standardized manner, it would be very difficult for results to be compared among different research groups ${ }^{[6]}$. Therefore, the primary objective of this article was to review some of the essential parameters that critically influence the in vitro bond strength results.

\section{VARIABLES AFFECTING BOND STRENGTH}

\section{Type of test}

It is well-established between authors that macro-tests "shear and tensile" with bonding surfaces around $7 \mathrm{~mm}^{2}$ exhibit lower bond strength values than their equivalent micro-tests with bonding surfaces around $1 \mathrm{~mm}^{2}$. Several studies were conducted using Clearfil SE Bond and Single Bond showed micro-bond values 2-3 times higher than their equivalent macro-bond values ${ }^{[7,8]}$. The overall increase in bond strength for small surfaces can be justified on the basis that an increase in specimen size increases the probability of presence of strength-limiting flaws that lower the ability of the specimen to resist the applied load during testing ${ }^{[9]}$. It was reported by many authors that the tensile bond strength has an inverse relationship with the bonded surface area. This means that the smaller the bonding surface, the higher the bond strength values ${ }^{[10]}$.

By comparing results of bond strength investigations for both shear and tensile mode of loading based on the surface area for the same adhesive systems, it was found that microtensile bond values were 2-5 times higher than that recorded by macrotensile test. For shear testing, the microshear bond values were 1.2-3 higher than those revealed by the macroshear test ${ }^{[11,12]}$. In addition, studies revealed higher average macroshear bond values than macrotensile ones ${ }^{[13,14]}$. This finding was explained on the basis that stresses applied to the test specimen in case of shear testing is far greater than that in case of tensile mode. For a given bonding area, the bond strength is measured by dividing the load at failure over the bonding area which will be higher in case of shear test than in case of tensile test.

Despite the simplicity by which the macrotests are conducted, there have been many studies and reviews that prefer the application of microtests to evaluate the bond strength at the tooth/restoration interface. A lot of advantages for these tests were mentioned ${ }^{[15]}$. These include: i) less or no flaws present in the test specimen which, in turn, produces higher bond strength than macrotests, ii) more adhesive failures and fewer cohesive failures compared to the macrotests, iii) testing of multiple specimens per tooth, iv) ability to test irregular surfaces and very small areas, and v) easier examination (By Scanning Electron Microscope SEM or Transmission Electron Microscope TEM) of failed bonds since the surface area is approximately $1 \mathrm{~mm}^{2}$. However, these microtests reported some drawbacks. These limitations include: i) technically demanding, ii) difficult to measure very low bond strength (<5 MPa), iii) specimens easily dehydrate, iv) specimens easily damaged, v) post-fracture specimens can be lost or damaged when removing from active gripping devices that use glue, and vi) difficult to fabricate with consistent geometry and surface finish ${ }^{[10,16]}$.

\section{Type of adhesive system}

Generally speaking, adhesive systems used to be classified by whether an etching acid is applied to the tooth structure and rinsed or left without rinsing. These two classes are referred to as 
"etch-and-rinse" or "no-rinse" systems respectively. The "etch-and-rinse" type is composed of either three- or two-step systems, in which the first step involves the application of an etching acid. Sometimes, the etch-and-rinse two-step system is referred to as a "one-bottle system", despite the need for two steps.

The "one-bottle system" is composed of a solution that contains primer and adhesive resin components ${ }^{[1,17-19]}$.

The "no-rinse" type is generally referred to as "self-etching" adhesive system. This can involve either two- or one-step applications. In the two-step system, the first step is to demineralize and prime the tooth surface, while the second step is to apply the adhesive layer to which the resin material will be bonded. In "one-step" adhesive systems, the tooth surface is demineralized, primed and bonded in a single application ${ }^{[19,20]}$.

The mode of application and compositional variations are the main differences between the marketed adhesive systems. These differences account for the variation in tooth/restoration bond strength "in vitro" as well as their clinical performance "in vivo" [21]. It has been reported by many authors ${ }^{[22-24]}$ that "etch-and-rinse" adhesives produce greater and more durable dentin-resin bonds than those produced by most of one- and two-step adhesives. It was reported that the "twostep" adhesive systems can form bonds with enamel comparable to that formed by "three-step" systems because of their ability to wet and impregnate the etched enamel ${ }^{[25]}$. On the contrary, bonds formed by these adhesives with dentin structure are less effective. This is because of incomplete diffusion of the adhesive under wet bonding conditions leaving a porous collagen network in place ${ }^{[26,27]}$.

Moreover, a study conducted by Scherrer et al. ${ }^{[14]}$ in which the authors collected all dentin bond strength data for six adhesive systems - of different types - with four tests (shear, microshear, tensile and microtensile) and critically analyzed the results with regard to average bond strength and product ranking. They found that, with the exception of microshear test, the three-step adhesive systems always recorded the top results followed by the two-step adhesive systems. The one-step adhesives always ranked low.

When "one-step self-etch" adhesive systems are used, a variety of problems may arise. Any of these can be a critical obstacle in adhesion process. These may include: i) water flow-off from the bonded dentin results in a dilution of the concentration of the adhesive monomers. This, in turn, lowers their inward rates of diffusion resulting in lower bonding ${ }^{[28-30]}$, ii) joining an acid with hydrophilic and hydrophobic monomers into a single solution may compromise the function of each one of these components ${ }^{[31]}$, iii) to keep these adhesives blended in solution, relatively high concentration of solvent is required. If this is the case, air-drying is not able to accomplish significant solvent evaporation ${ }^{[32]}$, and iv) the retention of water/HEMA solvents within the hybrid layer adversely affects polymerization. This results in reduced mechanical properties and ineffective dentin-resin bonding ${ }^{[32,33]}$.

\section{Resin-composite material}

\section{i) Elastic modulus}

It has been found that the elastic modulus of resin-composite restoratives varies widely from one material to another. The magnitude of the elastic modulus depends primarily on filler content ${ }^{[34,35]}$. However, there are other contributing factors such as the monomer composition ${ }^{[36]}$, degree of conversion ${ }^{[37,38]}$, and the curing mode ${ }^{[39,40]}$.

For maintaining a good resin-dentin bonding, there is a debate whether to use a resin-composite with high or low elastic modulus ${ }^{[41]}$. When the C-factor of a resin-based restoration is high, there is a risk of gap formation as a result of the polymerization contraction stress. In this case, it 
is recommended to use a resin-composite with low elastic modulus. A low modulus reduces the stresses at the dentin-resin interface and increases the probability that the bond between the resincomposite and the cavity walls remains intact ${ }^{[42,43]}$. However, when the restoration polymerization is complete, stresses may be generated by a different source. When the restored tooth is in contact with the opposing cusp, occlusal loading will create stresses at the tooth/restoration interface. Consequently, the marginal integrity may be at risk and debonding may take place. In this case, it has been recommended to use a resin-composite with high elastic modulus to resist the masticatory forces ${ }^{[35,44,45]}$.

It was reported that the use of a resin-composite with high elastic modulus may significantly increase bond strength values ${ }^{[46]}$. Though weak, a statistically significant correlation was observed between dentin shear bond strength and flexural strength of a resin-composite ${ }^{[47]}$ and between dentin tensile bond strength and mechanical properties of another resin-composite ${ }^{[48]}$. A study ${ }^{[49]}$ conducted to investigate the effect of elastic modulus of resincomposite materials on stress distribution at the bonded interface revealed that stress concentration at the bonded interface decreased as the elastic modulus increased from $6 \mathrm{GPa}$ to $12 \mathrm{GPa}$. Another study reported that the effect of the elastic modulus on dentin-resin bonding seems to be dependent on the adhesive system used for bonding ${ }^{[50]}$.

\section{ii) Consistency}

In case of lab-based testing of bond strength for deep cavities, the application of a low-viscosity resin composite before applying the restorative resincomposite proved to be helpful. It was demonstrated by Kemp-Scholte and Davidson [51] that an intermediate layer of unfilled resin between the adhesive resin and the restorative resin-composite relieved the polymerization contraction stress of the resin-composite by about $20-50 \%$. It was thought that the use of such a layer may act as an elastic buffer to relieve the stresses within the restorative material generated by polymerization contraction, thermal changes and occlusal forces keeping a good bonding at the tooth/restoration interface ${ }^{[52]}$.

Other studies ${ }^{[53,54]}$ reported that the use of low-viscosity "flowable" resin-composites have been advised for deep parts of class II cavities under hybrid or packable resin-composites. These materials believed to act as a stress-absorbing layer at the dentin-resin interface by partially reducing the stresses generated by the polymerization shrinkage. The low elastic moduli and enhanced flow capacity may provide more contraction stress relaxation and reduce the possibility of debonding ${ }^{[55]}$. Even in case of bond disruption between the tooth structure and the restorative resin-composite, the low-viscosity resin may help in keeping the dentinal tubules sealed against the ingress of bacteria and oral fluids ${ }^{[56]}$.

\section{iii) Placement technique}

There have been many studies conducted to evaluate the effect of placement techniques on the marginal sealing and dentin-resin bonding ${ }^{[57-}$ 59]. Most of these studies recommended the use of incremental placement techniques if a reduction in contraction stress and improvement in marginal seal are required. However, other studies reported debatable results. This debate was based on that not only the placement technique is the only factor in controlling the contraction stress and marginal integrity, but also the adhesive system, the type of resin-composite and the cavity forms ${ }^{[60-62]}$.

Moreover, the use of layering technique for resincomposite restorations can effectively influence the cavity configuration factor " $\mathrm{C}$-factor" and the magnitude of the polymerization shrinkage of the material used. This can be interpreted on the basis that when the restorative material is applied in a series of thin layers, one after another, the polymerization contraction of the resin-composite occurs within each layer individually, and so there is a larger 
unbonded surface to permit resin flow during each polymerization. In such a case, the C-factor is lower which will reduce the polymerization shrinkage stress. When successive layers are applied and irradiated, each layer of resin can compensate for polymerization shrinkage and stress accumulation in the previous one, increasing the strength of the bond with the dentin and reducing the possibility of microleakage. ${ }^{[57,63]}$.

On the other hand, several studies reported poor marginal adaptation and lower bond strength for bulk-filling techniques. Two major factors may contribute to these limitations of bulk-filling of resin-composite restorations: polymerization contraction stresses created during light-irradiation of a great volume of the restorative material and inadequate polymerization at the bottom of the cavity. The former can cause bond breakdown at the dentin-resin interface and the latter can cause premature failure of bulk-filled restorations ${ }^{[64,65]}$.

\section{iv) Polymerization shrinkage stress}

Polymerization shrinkage of a resin-based restorative has the potential to create contraction stresses that may disrupt the bond to the cavity walls. Many authors have been considering the competition between the mechanical stress in polymerizing resin-composite and the bonds of adhesive resin to the walls of restorations one of the main causes of marginal failure and subsequent microleakage observed with resin-composite restorations ${ }^{[63,66]}$.

Upon exposure to a light curing source, lightcured resin-composites usually exhibit a certain degree of contraction that ranges from $2 \%$ to $4 \%$ of its volume ${ }^{[67]}$. It is widely accepted between authors that volumetric contraction and solidification during the polymerization process of restorative resincomposites together with bonding to the hard tissue result in stress transfer and inward deformation of the cavity walls of the restored tooth. The shrinkage stresses are transferred to the surrounding tooth structure since it restricts the volumetric changes. The more polymerization shrinkage, the greater stresses are transferred. These stresses have the potential to cause deformation of the cavity wall and initiate a failure of the resin-dentin bonding ${ }^{[68,69]}$. It has been reported, however, that polymerization shrinkage stresses can be overcome partially by selecting a suitable placement technique, lowering the $\mathrm{C}$-factor which relates the bonded cavity surfaces to the unbonded ones, and choosing a resin-composite with a slowly-growing elastic modulus which gives a chance for shrinkage compensation particularly at the early stage of polymerization ${ }^{[70,71]}$.

\section{v) Mode of curing}

It was reported by several studies that polymerization contraction stress is generated at the bonding interface at a greater rate in case of light-cured resin-composites than those chemicallycured. This was explained on the basis that lightcured resin-composites polymerize at a faster rate than chemical-cured ones ${ }^{[72,73]}$. A reduction of polymerization rate of light-cured materials was suggested by decreasing the light intensity. However, this approach is thought to decrease the degree of conversion which will adversely affect the mechanical properties of the resin-composite with poor clinical performance of its restorations ${ }^{[73,74]}$.

The reduction of polymerization stress is majorly believed to take place during the first $10 \mathrm{~s}$ of light curing ${ }^{[72]}$. Therefore, the "soft-start" curing modes, such as the two-step mode and the ramping mode have been developed. These curing approaches were thought to effectively minimize shrinkage stress during polymerization reaction ${ }^{[75,76]}$.

\section{Bonding area}

Bonding area has been an important variable affecting the magnitude of bond strength at the toothrestoration interface. In case of "macro" test, either shear or tensile, the choice the bonding area area is 
usually made based on the substrate area available. More attention was paid to the relationship between the bonding area and the resulting strength with the development of micro-shear and micro-tensile tests ${ }^{[8,10]}$. Several investigations have been conducted to assess the impact of bonding area on the bond strength at the tooth/restoration interface ${ }^{[8,77]}$. Most of these studies revealed an inverse relationship between the bonding area and the resulting strength when tested either in tension or shear.

The relationship between bonding area and resulting strength was explained by what is called "fracture mechanics" that was initially derived from a series of experiments conducted by Griffith [78]. From these investigations, he reported that the strength of a solid elastic body is governed by the presence of microscopic flaws. Later on, Irwin ${ }^{[79]}$ defined the parameters involved in crack propagation. In short, failure of the bonded interface occurs when a crack propagates from a critical size flaw found in an area subjected to high stresses. The larger the bonding area, the higher is the probability of a flaw of critical size to exist and, consequently, the lower is the bond strength of the test specimen.

\section{Type and location of bonding substrate}

One more factor which has an influence on the measured bond strength is the type of dentin surface to which the resin-composite is applied. Several studies conducted by different research groups using varied adhesive systems revealed a greater bond strength for the dentin just below the dentinoenamel junction than that for the dentin near the pulp ${ }^{[80-82]}$. Moreover, investigations exhibited lower dentin bond strength for occlusal dentin when compared with proximal or buccal dentin ${ }^{[83,84]}$. Variations in dentin-resin bond strength in different dentin locations was attributed to several factors such as dentin wetness, permeability, thickness, calcification, direction and distribution of dentinal tubules ${ }^{[85]}$.

In addition, bonding to sclerotic dentin reported lower strength results compared to normal dentin.
This was justified on the basis that sclerotic dentin is less sensitive to etching agents than normal dentin substrates. Also, the dentinal tubules of such a dentin are generally occluded by mineral crystals ${ }^{[86-88]}$.

Two substrates have been used by researchers to conduct investigations on the tooth-restoration bonding: human and bovine teeth. It was reported that the best substrate for bonding would be living human dentin. However, the difficulty with "in vivo" bond strength studies has led to the extensive use of extracted teeth for the "in vitro" investigations. Because of their availability and larger size, bovine teeth have been utilized as s substitute for human teeth ${ }^{[6,83]}$. The use of young bovine incisor teeth proved to be a suitable and practical substrate for evaluating the bond strength of dental restoratives to the tooth structure. However, differences in the overall structure of bovine and human tooth structure could result in differences in the bonding results ${ }^{[89]}$.

\section{Treatment of bonding substrate}

It was reported by a number of studies that treating the tooth substrate to be bonded to the resincomposite restoration with chemicals can affect the bond strength. One of these chemicals is the hydrogen peroxide "HP" solution. Cocentrated HP is used in dental practice to bleach endogenous and exogeous discoloration of teeth ${ }^{[89]}$.

Researches have revealed a marked reduction in the bond strength when a light-cured resin is applied to bleached enamel shortly after exposure to HP. This reduction is said to be time-dependent. The SEM examination of failed resin/bleached enamel specimens suggested that there was an interaction between the HP and the restorative resin material at or close to the enamel surface, in addition to residual HP that could prevent adequate bonding at the resin-enamel interface ${ }^{[00]}$.

However, to restore the ability of the enamel substrate to effectively bond to the resin, some studies recommended immersion of bleached 
enamel in water for a period of time. In other words, it was reported that it may be possible to eliminate the HP from the interprismatic spaces by exposing the bleahed enamel to water for an extended period of time before the application of the resincomposite. This could restore the adhesive capacity to the pre-bleach values ${ }^{[91]}$.

\section{Storage conditions}

Storage conditions were said to have a critical effect on the tooth-resin bonding. Storage in distilled water for $24 \mathrm{~h}$ was reported to be sufficient to compare different restorative materials for their capabilities to withstand a wet environment. Also, it has been recommended that adhesion specimens should be subjected to a long-term water storage for better simulation of clinical conditions ${ }^{[84]}$.

With regard to the period of storage after resindentin bonding and before bond testing, there appears to be some disagreement between authors. It was stated by Hirasawa et al. ${ }^{[92]}$ that at least 24 $\mathrm{h}$ of storage should be allowed for polymerization shrinkage of the resin-composite to occur and for the resin-composite to equilibrate with water. It was reported that water equilibration may take up to seven days according to the filler content of the material. Prolonged storage of specimens, however, may have an adverse effect on the test results. Causton ${ }^{[83]}$ stated that the glycans of the dentinal proteins might be affected by long-term storage. He also thought that water could cause an unnatural increase in the dimensions of the dentin. This dimensional increase could build in a stress which would not be seen in the clinical situation.

With respect to the effect of post-extraction time on the bonding results, the great deal of literature studies indicated that it has no significant effect on dentin or enamel bonding. However, there are some studies reporting that post-extraction dentin does change and this change may have an effect on the resin-dentin bonding ${ }^{[93]}$.

\section{Smear layer}

For an acceptable tooth-restoration bonding, it is mandatory to optimize the tooth substrate to which the resin-composite will be bonded. Substrate optimization requires the removal or dissolution of barrier layers (smear layer) that interfere or inhibit the primer interaction with the bonding materials (adherends). Tooth surface preparation for bonding involves the use of acids for the removal of smear debris and selective dissolution of apatite crystals from the enamel and dentin. This later action creates micropores on the tooth surface through which the resin can penetrate and enhance bonding. One more action to the acid treatment is that it increases the surface energy of the enamel and dentin which will have a positive influence on the bonding quality ${ }^{[94]}$.

At one time, most commercial adhesive systems recommended the removal or dissolution of smear layer to achieve a good bonding between the dentin substrate and the applied bonding agent. This direction was taken because of the belief that insufficient penetration of monomers into the smear layer will prevent adequate dentin-resin bonding ${ }^{[95,96]}$. With the introduction of smear-removal reagents, dentin primers, and bonding agents, a great improvement in the dentin-resin bonding has been achieved. It was demonstrated that the interpenetration of monomers into the dentin and subsequent polymerization formed a "hybrid layer" that resulted in tight adhesion of the resins to dentin ${ }^{[97,98]}$.

In early studies, it was reported that majority of bond failures were thought to be "adhesive" in nature. However, careful SEM examination of both sides of failed bonds made to smear layers revealed that the failure was not adhesive but that the smear layer failed "cohesively". This was verified by the fact that both sides of the failed bond were covered by smear layer particles. This was because the bonds were made to smear layer-covered dentin not to the main dentin substrate ${ }^{[99]}$.

Later studies, on the other hand, proved that it is possible to keep the smear layer in situ or modify 
it with the production of adequate dentin-resin bonding. The reason behind preserving the smear layer was because of its expected action of sealing the open dentinal tubules and preventing dentin sensitivity ${ }^{[100]}$.

\section{SUMMARY}

From the information presented, one can realize the reason behind scattering and inconsistencies of bond strength results. Because of the many parameters that affect the bond testing and inability to control all of them in one test, differences in results have to arise. A great deal of efforts have to be done by authors to standardize these test parameters to enable a valid and reliable comparison between adhesive products and restorative materials.

\section{REFERENCES}

1. Stangel I, Ellis TH, Sacher E. Adhesion to Tooth Structure Mediated by Contemporary Bonding Systems. Dental Clinics of North America 2007; 51: 677-694.

2. Niu Y, Ma X, Fan M, Zhu S. Effects of layering techniques on the micro-tensile bond strength to dentin in resin composite restorations. Dental Materials 2009; 25: 129-134.

3. Finger WJ. Dentin bonding agents. Relevance of in vitro investigations. American Journal of Dentistry 1988; 1:184188.

4. Sudsangiam S, van Noort R. Do dentin bond strength tests serve a useful purpose? Journal of Adhesive Dentistry 1999; 1: 57-67.

5. Armstrong S, Geraldeli S, Maia R, Raposo LHA, Soares JS, Yamagawa J. Adhesion to tooth structure: A critical review of "micro" bond strength test methods. Dental Materials 2010; 26: 50-62.

6. Rueggeberg FA. Substrate for adhesion testing to tooth structure: review of the literature. Dental Materials 1991; 1: $2-10$.

7. Abdalla AI. Microtensile and tensile bond strength of single-bottle adhesives: a new test method. J Oral Rehabil 2004; 31:379-84.

8. Phrukkanon S, Burrow MF, Tyas MJ. Effect of cross-sectional surface area on bond strengths between resin and dentin. Dental Materials 1998; 14:120-128.
9. Burrow MF, Thomas D, Swain MV, Tyas MJ. Analysis of tensile bond strengths using Weibull statistics. Biomaterials 2004; 25:5031-5035.

10. Sano H, Shono T, Sonoda H, Takatsu T, Ciucchi B, Carvalho R, Pashley DH. Relationship between surface area for adhesion and tensile bond strength-evaluation of a microtensile bond test. Dent Mater 1994; 10:236-240.

11. Escribano NI, Del-Nero MO, de la Macorra JC. Inverse relationship between tensile bond strength and dimensions of bonded area. Journal of Biomedical Material Research B Applied Biomaterials 2003; 66: 419-424.

12. Cardoso PE, Braga RR, Carrilho MR. Evaluation of micro-tensile, shear and tensile tests determining the bond strength of three adhesive systems. Dental Materials 1998;14: 394-398.

13. Leloup G, D'Hoore W, Bouter D, Degrange M, Vreven J. Meta-analytical review of factors involved in dentin adherence. J Dent Res 2001; 80:1605-1614.

14. Scherrer SS, Cesar PF, Swain MV. Direct comparison of the bond strength results of the different test methods: A critical literature review. Dental Materials 2010; 26:78-93.

15. Pashley DH, Sano H, Ciucchi B, Yoshiyama M, Carvalho RM. Adhesion testing of dentin bonding agents: a review. Dental Materials 1995;11: 117-125.

16. Pashley DH, Carvalho RM, Sano H, Nakajima M, Yoshiyama M, Shono Y, et al. The microtensile bond test: a review. Journal of Adhesive Dentistry 1999;1: 299-309.

17. Miranda C, Prates LH, Vieira Rde S, et al. Shear bond strength of different adhesive systems to primary dentin and enamel. Journal of Clinical Pediatric Dentistry 2006; 31(1):35-40.

18. Turkun SL. Clinical evaluation of a self-etching and a onebottle adhesive system at two years. Journal of Dentistry 2003; 31(8):527-534.

19. Moszner N, Salz U, Zimmerman J. Chemical aspects of self-etching enamel-dentin adhesives: a systematic review. Dent Mater 2005; 21(10):895-910.

20. Kamada K, Yoshida K, Taira Y, et al. Shear bond strengths of four resin bonding systems to two silica-based machinable ceramic materials. Dent Mater J 2006; 25(3): 621-625.

21. Perdigao J, Gomes G, Duarte S Jr, et al. Enamel bond strengths of pairs of adhesives from the same manufacturer. Oper Dent 2005; 30(4):492-499. 
22. Pashley DH, Tay FR, Breschi L, Tjaderhane L, Carvalho RM, Carrilho M, Tezvergil-Mutluay A. State of the art etch-and-rinse adhesives. Dental Materials 2011; 27:1-16.

23. Cadenaro M, Breschi L, Rueggeberg FA, Suchko M, Grodin E, Agee KA, Di Lenarda R, Tay FR, Pashley DH. Effects of residual ethanol on the rate and degree of conversion of five experimental resins. Dental Materials 2009; 25:621-628.

24. Hashimoto M, Ito S, Tay FR, Svizero NR, Sano H, Kaga M, Pashley DH. Fluid movement across the resin-dentin interface during and after bonding. Journal of Dental Research 2004; 11: 843-848.

25. Van Meerbeek B, De Munck J, Yoshida Y, et al. Buonocore memorial lecture: adhesion to enamel and dentin. Current status and future challenges. Operative Dentistry 2003; 28(3):215-235.

26. Spencer P, Wang Y, Walker MP, et al. Interfacial chemistry of the dentin/adhesive bond. Journal of Dental Research 2000; 79(7):1458-1463

27. Miyazaki M, Onose H, Moore BK. Analysis of the dentinresin interface by use of laser Raman spectroscopy. Dental Materials 2002; 18(8): 576-580.

28. Carvalho RM, Chersoni S, Frankenberger R, Pashley DH, Prati C, Tay FR. A challenge to the conventional wisdom that simultaneous etching and resin infiltration always occurs in self-etch adhesives. Biomaterials 2005;26: 10351042 .

29. Wang Y, Spencer P. Continuing etching of an all-in-one adhesive in wet dentin tubules. Journal of Dental Research 2005; 84:350-354.

30. Hiraishi N, Nishiyama N, Ikemura K, Yau JY, King NM, Tagami J, et al. Water concentration in self-etching primers affects their aggressiveness and bonding efficacy to dentin. Journal of Dental Research 2005; 84:653-658.

31. Tay FR, Pashley DH, Garcia-Godoy F, Yiu CK. Singlestep, self-etch adhesives behave as permeable membranes after polymerisation. Part II. Silver tracer penetration evidence. American Journal of Dentistry 2004; 17:315-322.

32. Nunes TG, Ceballos L, Osorio R, Toledano M. Spatiallyresolved photopolymerization kinetics and oxygen inhibition in dental adhesives. Biomaterials 2005; 26:1809-1817.

33. Yiu CK, Pashley EL, Hirashi N, King NM, Goracci C, Ferrari $\mathrm{M}$, et al. Solvent and water retention in dental adhesive blends after evaporation. Biomaterials 2005; 26:68636872 .
34. Braem M, Finger W, van Doren VE, Lambrechts P, Vanherle G. Mechanical properties and filler fraction of dental composites. Dental Materials 1989;5: 346-348.

35. Sabbagh J, Vreven J, Leloup G. Dynamic and static moduli of elasticity of resin-based materials. Dental Materials 2002; 18: 64-71.

36. Asmussen E, Peutzfeldt A. Influence of UEDMA, BisGMA and TEGDMA on selected mechanical properties of experimental resin composites. Dental Materials 1998; 14: 51-56.

37. Helvatjoglu-Antoniades M, Papadogiannis Y, Lakes RS, Dionysopoulus P, Papadiogiannis D. Dynamic and static elastic moduli of packable and flowable composite resins and their development after initial photo curing. Dental Materials 2006; 22:450-459.

38. Sakaguchi RL, Shah NC, Lim B-S, Ferracane JL, Borgersen SE. Dynamic mechanical analysis of storage modulus development in light-activated polymer matrix composites. Dental Materials 2002; 18: 197-202.

39. Peutzfeldt A, Asmussen E. Resin composite properties and energy density of light cure. Journal of Dental Research 2005; 84: 659-662.

40. Asmussen E, Peutzfeldt A. Flexural strength and modulus of a step-cured resin composite. Acta Odontologica Scandinavia 2004; 62:87-90.

41. Asmussen E, Peutzfeldt A. Class I and Class II restorations of resin composite: An FE analysis of the influence of modulus of elasticity on stresses generated by occlusal loading. Dental Materials 2008; 24: 600-605.

42. Kleverlaan CJ, Feilzer AJ. Polymerization shrinkage and contraction stress of dental resin composites. Dental Materials 2005; 21: 1150-1157.

43. Feilzer AJ, de Gee AJ, Davidson CL. Quantitative determination of stress reduction by flow in composite restorations. Dental Materials 1990; 6: 167-171.

44. Abe Y, Lambrechts P, Inoue S, Braem MJA, Takeuchi M, Vanherle G, et al. Dynamic elastic modulus of 'packable' composites. Dental Materials 2001;17: 520-525.

45. Lambrechts P, Braem M, Vanherle G. Evaluation of clinical performance for posterior composite resins and dentin adhesives. Operative Dentistry 1987; 12: 53-78.

46. Braga RR, Meira JBC, Boaro LCC, Xavier TA. Adhesion to tooth structure: A critical review of "macro" test methods. Dental Materials 2010; 26: 38-49. 
47. Thomsen KB, Peutzfeldt A. Resin composites: strength of the bond to dentin versus mechanical properties. Clinical Oral Investigations 2007; 11: 45-49.

48. Hasegawa T, Itoh K, Koike T, Yukitani W, Hisamitsu H, Wakumoto $\mathrm{S}$, et al. Effect of mechanical properties of resin composites on the efficacy of the dentin bonding system. Operative Dentistry 1999; 24: 323-330.

49. Van Noort R, Noroozi S, Howard IC, Cardew G. A critique of bond strength measurements. Journal of Dentistry 1989; 17: 61-67.

50. Kurokawa R, Finger WJ, Hoffmann M, Endo T, Kanehira M, Komatsu M, et al. Interactions of self-etch adhesives with resin composites. Journal of Dentistry 2007; 35: 923929.

51. Kemp-Scholte CM, Davidson CL. Complete marginal seal of class $\mathrm{V}$ resin composite restorations effected by increased flexibility. Journal of Dental Research 1990; 69: 1240-1243.

52. Van Meerbeek B, Willems G, Celis JP, Roos JR, Braem M, Lambrechts $\mathrm{P}$, et al. Assessment by nano-indentation of the hardness and elasticity of the resin-dentin bonding area. Journal of Dental Research 1993; 72: 1434-1442.

53. Behle C. Flowable composites: properties and applications. Practice periodontics and Aesthetic Dentistry 1998; 10: 347-351.

54. Leevailoj C, Cochran MA, Matis BA, Moore BK, Platt JA. Microleakage of posterior packable composites with and without flowable liners. Operative Dentistry 2001; 26: 302-307.

55. Montes MAJR, de Goes MF, Cunha MRB, Soares AB. A morphological and tensile bond strength evaluation of an unfilled adhesive with low-viscosity composites and a filled adhesive in one and two coats. Journal of Dentistry 2001; 29: 435-441.

56. Unterbrink GL, Liebenberg WH. Flowable resin composites as filled adhesives: literature review and clinical recommendations. Quintessence International 1999; 30: 249-257.

57. Rupp NW. Clinical placement and performance of composite resin restorations. Journal of Dental Research 1979; 58: 155-157.

58. Torstenson B, Oden A. Effects of bonding agent types and incremental techniques on minimizing contraction gaps around resin composites. Dental Materials 1989; 5: 218223.
59. Zidan O, Gomez-Marin O, Tsuchiya T. A comparative study of the effects of dentinal bonding agents and application techniques on marginal gaps in class V cavities. Journal of Dental Research 1987; 66: 716-721.

60. Crim GA. Microleakage of three resin placement techniques. American Journal of Dentistry 1991; 4: 69-72.

61. Linden J, Swift EJ. Microleakage of two new dentin adhesives. American Journal of Dentistry 1994; 7: 31-34.

62. Hansen EK. Effect of cavity depth and application technique on marginal adaptation of resins in dentin cavity. Journal of Dental Research 1986; 65: 1319-1321.

63. Davidson CL, de Gee AJ, Feilzer AJ. The competition between the composite-dentin bond strength and the polymerization contraction stress. Journal of Dental Research 1984; 63:1396-1399.

64. Gallo JR, Bates ML, Burgess JO. Microleakage and adaptation of class II packable resin-based composites using incremental or bulk filling techniques. American Journal of Dentistry 2000; 13: 205-208.

65. Yap AUJ. Effectiveness of polymerization in composite restoratives claiming bulk placement: impact of cavity depth and exposure time. Operative Dentistry 2000; 25: 113-120.

66. Carvalho RM, Pereira JC, Yoshiyama M, Pashley DH. A review of polymerization contraction: the influence of stress development versus stress relief. Operative Dentistry $1996 ; 21: 17-24$.

67. Labella R, Lambrechts P, Van Meerbeek B, et al. Polymerization shrinkage and elasticity of flowable composites and filled adhesives. Dental Materials 1999; 15: 128-137.

68. Kinomoto Y, Torii M. Photoelastic analysis of polymerization contraction stresses in resin composite restorations. Journal of Dentistry 1998; 26:165-171.

69. Kinomoto Y, Torii M, Takeshige F, et al. Polymerization contraction stress of resin composite restorations in a model Class I cavity configuration using photoelastic analysis. Journal of Esthetic Dentistry 2000; 12:309-319.

70. Feilzer AJ, De Gee AJ, Davidson CL. Setting stress in composite resin in relation to configuration of the restoration. Journal of Dental Research 1987; 66: 1636-1639.

71. Nakajima M, Sano H, Burrow MF, et al. Tensile bond strength and SEM evaluation of caries-affected dentin using dentin adhesives. Journal of Dental Research 1995; $74: 1679-1688$. 
72. Feilzer AJ, de Gee AJ, Davidson CL. Setting stress in composites for two different setting modes. Dental Materials 1993; 9: 2-5.

73. Bouschlicher MR, Vargas MA, Boyer DB. Effect of composite type, light intensity, configuration factor and laser polymerization on polymerization contraction forces. American Journal of Dentistry 1997; 10: 88-96.

74. Silikas N, Eliades G, Watts DC. Light intensity effects on resin-composite degree of conversion and shrinkage strain. Dental Materials 2000; 16: 292-296.

75. Ernst CP, Kürschner R, Rippin G, Willershausen B. Stress reduction in resin-based composites cured with a two-step light-curing unit. American Journal of Dentistry 2000; 13: 69-72.

76. Lim BS, Ferracane JL, Sakaguchi RL, Condon JR. Reduction of polymerization contraction stress for dental composites by two-step light-activation. Dental Materials 2002; 18: 436-44.

77. Poitevin A, De Munck J, Van Landuyt K, Coutinho E, Peumans M, Lambrechts $\mathrm{P}$, et al. Critical analysis of the influence of different parameters on the microtensile bond strength of adhesives to dentin. Journal of Adhesive Dentistry 2008;10:7-16.

78. Griffith AA. The phenomena of flow and rupture in solids. Philosophical Transactions of the Royal Society 1921; 221: $163-198$.

79. Irwin GR. Analysis of stresses and strains near the end of a crack traversing a plate. Journal of Applied Mechanics 1957; 24: 361-364.

80. Causton BE. Improved Bonding of Composite Restorative to Dentin. British Dental Journal 1984; 156: 93-95.

81. Mitchem JC, Gronas DG. Effects of time after extraction and depth of dentin on resin dentin adhesives. Journal of American Dental Association1986; 113:285-287.

82. Tao L, Pashley DH. Shear bond strength to dentin: Effects of surface treatments, depth and position. Dental Materials 1988; 4:371-378.

83. Causton BE. In vitro assessment of dentin bonding agents. In: Today's Dentist, Proceedings of international symposium on adhesion, its theory and practice in restorative dentistry, special edition 1987. London: Current Medical Literature Ltd., 18-27.

84. Oilo G, Olsson S. Tensile bond strength of dentin adhe- sives: A comparison of materials and methods. Dental Materials $1990 ; 6: 138-144$.

85. Prati C, Pashley DH. Dentin Wetness, permeability, thickness and bond strength of adhesive systems. American Journal of Dentistry 1992; 5: 33-38.

86. Gwinnett AJ. Interfacial morphology of resin composite and shiny erosive lesions. American Journal of Dentistry 1991; 5: 315-317.

87. Nara Y, Katsuyama S, Dogon IL. A comparison of the adhesion of two new restorative systems to dentin with wedge-shaped defects. Journal of Dental Research 1994; 73: 130- Abstract.

88. Van Meerbeek B, Braem M, Lambrechts P, Venherle G. Morphological characterization of the interface between resin and sclerotic dentin. Journal of Dentistry 1994; 22:141-146.

89. Titley KC, Tornek CD, Smith DC, Adibfar A. Adhesion of composite resin to bleached and unbleached bovine enamel. Journal of Dental Research 1988; 67:1523-1528.

90. Tornek CD, Titley KC, Smith DC, Adibfar A. the influence of time of hydrogen peroxide exposure on the adhesion of composite resin to bleached and unbleached bovine enamel. Journal of Endodontics 1990; 16:123-128.

91. Tornek CD, Titley KC, Smith DC, Adibfar A. The influence of leaching on the adhesion of light-cured composite resin to bleached bovine enamel. Journal of Endodontics 1991; 17: 156-160.

92. Hirasawa T, Hirano S, Hirabayashi S, Harashima I, Aizawa M. Initial dimensional change of composite in dry ad wet conditions. Journal of Dental Research 1983; 62: 28-31.

93. Causton BE, Johnson NW. Changes in the dentin of human teeth following extraction and their implication for in vitro studies of adhesion to tooth substance. Archive of Oral Biology. 1979; 24:229-232.

94. Renzo M, El Feninat F, Jimenez-Esquivel B, et al. Adhesion to dentin: the role of chemical reactions in surface modification. Canadian Journal of Chemistry 1998; 76(1):1-6.

95. Joynt RB, Davis EL, Wieczkowski Jr G, Yu XY. Dentin bonding agents and the smear layer. Operative Dentistry 1999; 16:186-191

96. Triolo Jr PT, Swift Jr EJ. Shear bond strengths of ten dentin adhesive systems. Dental Materials 1992;8: 370-374. 
97. Nakabayashi N. Bonding of restorative materials to dentine: The present status in Japan. International Dental Journal 1985; 35: 145-154.

98. Hara T Hayakawa T. Studies on adhesion of MMA (TBBO) resin to dentin -The efficacy of the primer treatment. Journal of Japanese Dental Materials 1989; 8:608-616.
99. Tao L, Pashley DH (1988). Shear bond strength to dentin: Effects of surface treatments, depth and position. Dental Materials 1988; 4:371-378.

100. Hayakawa T, Nemoto K, Horie K. Adhesion of composite to polished dentin retaining its smear layer. Dental Materials $1995 ; 11: 218-222$. 